\title{
PSICANÁLISE E UNIVERSIDADE: QUESTÕES SOBRE A FORMAÇÃO DO ANALISTA E O ENSINO NA GRADUAÇÃO EM PSICOLOGIA
}

\author{
Lêda Lessa Andrade Filha Doutoranda em Psicologia pela UFBA. Professora da \\ Escola Bahiana de Medicina e Saúde Pública. \\ Psicóloga no Hospital Juliano Moreira, docente e \\ supervisora, do programa de Residência em \\ Psicologia Clínica e Saúde Mental
}

\begin{abstract}
Resumo
O presente artigo constitui-se em uma reflexão que encontra a sua inspiração na experiência de docência da autora no curso de Psicologia da Bahiana. Trata-se de um escrito que procura pensar questões relativas ao ensino da psicanálise em um curso de graduação em psicologia, cotejando-as com elementos referidos ao processo de formação de um analista. Para isto, a autora reflete sobre a condição do analista na posição de docente de um curso de psicologia, destacando os aspectos do ensino e da transmissão em psicanálise. São atualizadas algumas preocupações inscritas por Freud sobre a psicanálise "leiga", as quais deixam ver como a psicanálise é, a um só tempo, teoria, método e procedimento para trabalhar com os processos psíquicos, ou seja, é uma clínica. No mesmo ensejo de atualizar a discussão, são trazidas à reflexão questões contemporâneas postas por analistas em artigos recentes, voltadas à problematização do tema a partir de aspectos como a lide com a verdade no discurso da universidade, e o lugar da mestria, pontos que reverberam nas interrogações que a autora se faz, tecendo ponderações sobre a ética e a prática. Para finalizar, são mencionadas algumas experiências consideradas frutíferas à utilização do aporte teórico psicanalítico, e indicadas certas condições que se têm mostrado favoráveis a um aprendizado da psicanálise que permite preservar o seu estatuto de ser, ao mesmo tempo, uma teoria e uma clínica para trabalhar com os processos psíquicos.
\end{abstract}

Palavras-chave: Psicanálise; Ensino; Transmissão; Universidade.

\section{PSYCHOANALYSIS AND UNIVERSITY: QUESTIONS ABOUT THE FORMATION OF THE ANALYST AND TEACHING IN THE UNDERGRADUATE COURSE IN PSYCHOLOGY}

\begin{abstract}
This article is a reflection on which finds its inspiration in the author's experience teaching courses in Psychology of Escola Bahiana de Medicina e Saúde Pública (Bahia School of Medicine and Public Health). This is a writing that seeks to think of matters relating to the teaching of psychoanalysis in an undergraduate degree in Psychology, comparing them with elements referred to the process of formation of an analyst. For this, the author reflects on the condition of the analyst in the position of professor of a Psychology course, highlighting aspects of teaching and transmission in psychoanalysis. Some concerns listed by Freud about "lay" psychoanalysis are updated, which allow us to see how psychoanalysis is, at once, theory, method and procedure for working with psychic processes, i.e., it is a clinic. At the same opportunity to update the discussion, contemporary issues posed by analysts in recent articles are brought to reflection, aimed at questioning the theme from aspects such as dealing with the truth in the discourse of the university, and the place of mastery, points that reverberate in questions that the author herself does, weaving weights on the ethics and practice. Finally, some experiments mentioned are considered fruitful to the use of theoretical psychoanalysis, and indicated certain conditions that have shown a favorable learning of psychoanalysis that preserves its status of being simultaneously a theory and clinic for working with psychic processes.
\end{abstract}

Keywords: Psychoanalysis; Teaching; Transmission; University. 


\section{INTRODUÇÃO}

Em 2011, contabilizamos o décimo ano de trabalho no curso de psicologia da Bahiana. Consideramos o momento, pois, uma oportunidade importante para empreender algumas reflexões sobre a condição do analista na posição de docente de um curso de psicologia, relevando os aspectos do ensino e da transmissão em psicanálise. Deste modo, revisitaremos algumas questões concernentes à formação do analista, à contribuição da psicanálise na construção do saber e da prática psicológicos, à produção teórica, aos desafios da vivência interdisciplinar, e à realização da pesquisa.

Muito se tem interrogado sobre os efeitos, na formação do analista, de uma constatada migração, por assim dizer, dos espaços tradicionalmente destinados àquela formação - nomeadamente, as instituições de psicanálise - para os espaços universitários. As maiores preocupações se voltam para o aspecto de uma subordinação do saber analítico ao modus operandi da universidade, uma vez que este, pautado no ensino - e ainda que comprometido com a pesquisa e a extensão -, não é capaz de contemplar a potencialidade da transmissão que uma instituição psicanalítica oferece.

E nenhum ensino formal se dá abstraído do professor que dele se faz cargo. É este professor, portanto, comumente tributário de uma experiência de analista que lhe permite comunicar algo do vivido no campo da clínica, que se vê às voltas, constantemente, com situações que lhe vêm interrogar sua posição no ensino da psicanálise.

As reflexões às quais ora damos lugar advirão de um empenho pessoal em pensar a prática docente a partir da psicanálise, e se inspirarão em algumas questões levantadas pelo próprio Freud desde o início do seu trabalho, por Lacan em alguns momentos específicos do seu ensino, e ainda por analistas contemporâneos que se ocupam de problematizar o tema, dadas as particularidades e consequências do modo atual como a psicanálise tem tomado assento na universidade.

\section{A FORMAÇÃO DO ANALISTA: INSTITUIÇÃO E UNIVERSIDADE}

A fim de melhor situar as questões que ora trago para compartilhar com o leitor acerca do ensino da psicanálise na universidade, comentarei um pouco do meu próprio 
percurso na formação de analista e na escolha pela docência, destacando algumas peculiaridades destas trajetórias. Por isto, o uso da primeira pessoa do singular nos parágrafos a seguir.

Empreendi o meu processo inicial de formação na psicanálise percorrendo os caminhos estabelecidos desde muito cedo por Freud, e que se tornaram, por anos a fio, os únicos a ser trilhados por quem buscava uma formação: o ingresso em uma instituição psicanalítica, na qual realizava intensos estudos orientados pelos analistas mais experientes; ${ }^{1}$ a análise pessoal; e a supervisão no momento em que comecei a atender em consultório.

Quando, alguns anos mais tarde, foi-se consolidando o interesse pela docência, ingressei no mestrado e, durante o mesmo, tive já uma prática como professora. Algum tempo depois de findo o mestrado, comecei a ensinar na Bahiana, e também retornei aos atendimentos no ambulatório do Hospital Juliano Moreira, ${ }^{2}$ prática que pode ser considerada como psicanálise em extensão. Por fim, o ingresso no doutorado. Tenho transitado, portanto, entre vários espaços de trabalho com a psicanálise: o privado, o da psicanálise em extensão, e o da docência, seja como professora, seja como aluna.

\section{O laico e o universal}

Na pós-graduação, abre-se, frequentemente, a possibilidade de uma experiência com a psicanálise em muito distinta daquela que se dá na instituição, uma vez que ela é debatida no campo do diverso; ou, de outro modo dito, o específico da psicanálise surge ou se evidencia à diferença com outras esferas do saber (a filosofia, a sociologia, áreas distintas do conhecimento psicológico etc.). É certo que tais debates propiciam importantes desafios aos praticantes da psicanálise, uma vez que os levam a interrogar pressupostos, a dialetizar construções teóricas, a abrir o leque das referências com as quais férteis diálogos podem ser gerados.

\footnotetext{
${ }^{1}$ Creio ser importante comentar que, como muitos dos meus colegas, circulava também por outros institutos de psicanálise além do Colégio de Psicanálise da Bahia (então, Colégio Freudiano da Bahia), escutando aqui e ali diferentes modos de transmissão da teoria.

2 Trata-se de um hospital da rede pública estadual, especializado em saúde mental, que atende à população usuária do Sistema Único de Saúde.
} 
Mas não é esse o aspecto central da questão a preocupar os analistas. Se Freud já dizia, em 1919, ${ }^{(1,}$ p. 217) que "o psicanalista pode prescindir completamente da universidade", mas que a universidade só teria a ganhar com a inclusão da psicanálise nos seus currículos, em Lacan ${ }^{(2, \text { p. 439) }}$ temos uma inflexão da questão, sob a forma da pergunta que introduz o seu texto: “A psicanálise, o que ela nos ensina...como ensiná-lo?”.

A universidade, sabemos, não é o lugar aquilatado para a formação de um analista, uma vez que a análise pessoal não pode ser incluída nas exigências acadêmicas. Ademais, o saber produzido na universidade orienta-se pelo discurso científico, o qual traduz a aposta feita pela ciência de que o conhecimento é capaz de recobrir o real da experiência, deixando ver um determinado modo de operar com a verdade. A psicanálise, por sua vez, acentua, todo o tempo, outra dimensão na lide com a verdade, apontando sempre para a incompletude do saber, ${ }^{(3)}$ para o reconhecimento de que a verdade tem valor de mito, uma vez que não pode ser toda dita porque constituída pela palavra, "arruinando assim todas as esperanças fundadas em um conhecimento de nosso inconsciente que se sustentaria exclusivamente na compreensão racional de sua objetivação teórica". (4)

Essas eram, certamente, questões entrevistas por Freud, e comparecem, mesmo que formuladas de outro modo, no artigo referido acima, de $1919 .^{(1)}$ O seu outro artigo, $A$ questão da análise leiga, de $1926^{(5)}$ escrito sob a motivação de fazer uma defesa do exercício da psicanálise por não-médicos em um momento no qual Theodor Reik estava sendo acusado, em Viena, de charlatanismo, é uma peça muito especial sobre essa discussão ${ }^{3}$. Freud afirma que a ciência positiva, determinante na formação médica, dirigia os conteúdos das disciplinas para os campos da anatomia, da física e da química, tornandose falha no esclarecimento sobre os determinantes psíquicos nas doenças, falha que não se resolvia com a inclusão da psicologia médica nos currículos, uma vez que os estudos tinham base na psicologia experimental ou na acadêmica. A formação de um analista precisaria, além da biologia, conter conhecimentos ligados à história da civilização, à mitologia, à psicologia da religião, à "ciência da literatura" (a expressão é do próprio Freud). ${ }^{(5, \text { p. 278) }}$

\footnotetext{
${ }^{3}$ A construção do texto é muito interessante: Freud elege uma "pessoa imparcial" para ser sua interlocutora, e segue, passo-a-passo, argumentando com ela, respondendo às investidas contrárias que ela faria aos argumentos dele etc.
} 
No entanto, se por um lado a psicanálise não deveria quedar limitada ao campo da medicina, era preciso garantir que ela não ficasse como uma invenção menor. ${ }^{4}$ Nesse sentido, não foram poucos os esforços de Freud para ver a sua criação ter o devido tratamento de uma ciência. Em seu Dois verbetes de enciclopédia, por exemplo, diz que:

Psicanálise é o nome de ${ }^{(1)}$ um procedimento para a investigação de processos mentais que são quase inacessíveis por qualquer outro modo, ${ }^{(2)}$ um método (baseado nessa investigação) para o tratamento de distúrbios neuróticos $\mathrm{e}^{(3)}$ uma coleção de informações psicológicas obtidas ao longo dessas linhas, e que gradualmente se acumula numa nova disciplina científica. ${ }^{(6}$ p. 287)

Ele nos está a indicar, portanto, que a psicanálise pode ter garantido o seu lugar no estatuto das ciências: ela tem método próprio, objeto próprio, e um arcabouço teórico que lhe é específico. À sua maneira, parece que Freud tentou responder a uma certa exigência de formalidade que se demandava à psicanálise. Este não foi o único dos textos, de tom enciclopédico, dedicados à explicitação, para um público mais vasto, do que era a abordagem que fundara: há outras passagens, escritas a pedido de terceiros para publicações de áreas médicas e afins. Interessante notar, a propósito, o quanto essas passagens deixam ver que a psicanálise não é apenas uma coleção de enunciados sobre o funcionamento psíquico, ou uma teoria que se apresente unicamente como proposta epistemológica, mas sim, a um só tempo, teoria, método e procedimento para trabalhar com os processos psíquicos, ela é uma clínica. São planos indissociáveis, configurando o específico de uma disciplina que tem como desígnio não renunciar a dar a palavra ao sujeito.

Temos, pois, a psicanálise desfrutando do estatuto de ciência - ainda que não livre dos ataques de epistemólogos -, mas resguardando sua condição de um saber transmissível e não abarcado pela medicina. Esta se mantém uma questão bastante atual, sendo que hoje, por extensão, havemos de pensá-la, sobremaneira, com relação à psicologia, no sentido de que a psicanálise possa manter a sua especificidade, que não submerja nos cânones dos saberes psicológicos.

\footnotetext{
${ }^{4}$ Nos primórdios, o temor de Freud era que ela fosse considerada como restrita a um círculo de médicos judeus vienenses.
} 
Reitera-se então, a defesa de que a psicanálise possa se conservar leiga, a fim de preservar a sua ética e o compromisso com uma verdade que é sempre não-toda. Azevedo bem coloca a questão, retomando Lacan:

A análise é leiga por não ser uma especialidade, de disciplinas estabelecidas e supostamente afins, onde a dialética entre saber e verdade é subsumida em prol da certeza objetiva, da evidência, do princípio da não-contradição, atributos sobre os quais se assenta o caráter "verdadeiro" dos discursos científico. ${ }^{\text {(7. p. 9) }}$

\section{A instituição psicanalítica}

Não podemos deixar de mencionar, nesta espinhosa e não resolvida questão, que é a formação do analista em face da crescente procura pela universidade, o problema do aclamado dogmatismo de muitas das instituições de psicanálise. Não é nosso propósito nos delongarmos neste aspecto, mas é necessário comentá-lo, ainda que brevemente.

A criação da instituição psicanalítica foi uma maneira encontrada pelos pioneiros de garantir um espaço de formação no qual a troca entre os pares pudesse se dar, e houvesse a oportunidade de um reconhecimento mútuo. No artigo de $1926,{ }^{(5)}$ Freud se interroga se a prática de psicanálise deveria ficar sujeita a uma interferência oficial, ou se a mesma deveria seguir o seu curso "natural", pergunta que serve de mote para a sua crítica ao furor prohibendi, a seu ver excessivo, vigente na Áustria de então.

O fato é que o pós-guerra trouxe uma série de secessões nas sociedades psicanalíticas, e, por muito tempo, elas só puderam existir sob a tutela da IPA, a International Psychoanalytic Association, que apesar dos combates e críticas, cumpria seu papel de garantia, "nela depositava-se a esperança de existência de um núcleo inabalável para aquilo que poderia ser chamado de psicanálise". (8, p.121-2)

No decurso dos anos sessenta, um fato que viria a abalar os alicerces do establishment psicanalítico foi a excomunhão de Lacan da IPA. Com os vários que o acompanharam na saída, ele fundou a Sociedade Francesa de Psicanálise, e fez ver a possibilidade da existência da psicanálise e da formação do analista fora da salvaguarda da 
IPA. ${ }^{5}$ Este e outros tantos atos tiveram uma enorme repercussão no meio intelectual e na transmissão da psicanálise em vários países no mundo, inclusive na América Latina, fazendo-nos concordar com Miguelez: “Queiramos ou não, saibamos ou não, gostemos ou não, todos nós [ligados à causa analítica] somos, de alguma forma, herdeiros do legado inaugurado por Lacan”. (8, p.122, inserção nossa)

A proliferação de instituições psicanalíticas de orientação lacaniana foi-se dando no decorrer do tempo, demonstrando uma oposição ao dogmatismo da IPA, e permitindo uma renovação da psicanálise e o franqueamento da formação a um número muito maior de pessoas. ${ }^{(9)}$ No cerne deste fenômeno, reside a aposta de que o saber não se cristalize, não se encarne na figura de um mestre, permitindo que a formação verdadeiramente aconteça, resguardando o tripé da análise pessoal, do estudo teórico, e da supervisão.

Entretanto, o fenômeno da crescente oferta de cursos de psicanálise nas universidades e faculdades, com uma consequente procura deles por psicólogos e analistas, ${ }^{6}$ tem conduzido à interrogação daquilo que porventura estaria a ocorrer nas instituições psicanalíticas. Nas tentativas de entendimento do problema, para além das avaliações que levam em conta fenômenos da contemporaneidade e a crise da modernidade que também atinge a psicanálise, aponta-se para fatores como certa inibição do pensamento criativo no interior das instituições, e o retorno a modelos autoritários de funcionamento, com o saber gravitando em torno de determinados membros que ocupam o lugar de mestres. Não podemos deixar de comentar, também, o crescente interesse pela obtenção de títulos por parte dos estudantes, em nome do entendimento que têm daquilo que seriam as demandas do "mercado de trabalho".

\section{ENSINO E TRANSMISSÃO}

Temos, pois, que a inserção da psicanálise na universidade tornou-se um fato, e, ao mesmo tempo, uma convocação à reflexão inspirada em princípios que a ética psicanalítica

\footnotetext{
${ }^{5}$ Recordemos que Lacan foi, entre os analistas, talvez o primeiro grande responsável por levar o ensino da psicanálise para a universidade, ainda que o estabelecesse de modo muito singular através das aulas dos seus seminários.

${ }^{6}$ Importante lembrar que a frequência aos cursos vem sempre acompanhada da exigência de uma produção formal, qual seja, o artigo, a monografia, a dissertação, a tese...
} 
apresenta. Desde que ingressamos no curso de psicologia da Bahiana, e uma vez envolvidos com componentes curriculares voltados à psicanálise, ${ }^{7}$ foi sempre uma preocupação garantir o ensino sem perder de vista a transmissão, desafio que pode ser colocado mais ou menos nos seguintes termos: Como fazer para se encarregar de uma tarefa regulada pelos discursos da mestria e da universidade, na qual estão em pauta avaliações conceituais e atitudinais, mas desempenhá-la sob a assertiva de que o saber é sempre incompleto, de que a transferência joga seu lugar no aprendizado, de que aprender envolve invenção e criação? E, ainda mais especificamente, pois se trata de psicanálise, como transmiti-la para pessoas que, em sua maioria, terão dela apenas uma apreensão teórico-conceitual, sem passar pela experiência da análise pessoal?

É certo que, apesar dos nossos esforços, convicções e modos de trabalhar, equilibrar esses elementos nem sempre se faz possível - até porque isto só se materializa na medida em que, instaurada a falta, há um encontro do desejo no outro. Mas há que se renovar a aposta, explorando aqui e ali as possibilidades que se apresentam. Na trama das aulas, dos planos semestrais, das reuniões de coordenação, das conversas entre colegas, das atividades várias dentro e fora da sala de aula, fica o ensejo de que possamos ensinar permitindo as construções e elaborações de sentido por cada um dos nossos alunos, buscando resguardar a escuta da palavra do estudante, das suas elaborações, valorizar as questões produzidas nos debates.

Nos últimos dez anos, têm sido frequentes os esforços no curso de psicologia para realizar ações interdisciplinares, nas quais o saber psicanalítico é posto no lugar de "um entre vários", contribuindo sempre que possível. Um outro espaço interessante são as orientações dos trabalhos de conclusão de curso: há aqueles TCC's cuja proposta, desde o princípio, é concebida a partir da psicanálise, vindo esta em auxílio no estudo de situações oriundas das práticas de estágio (tanto na clínica, quanto em outros campos), ou instigadas por motivações ou curiosidades mais pessoais. E há aqueles outros trabalhos, que versam sobre temas contemporâneos, para os quais a psicanálise entra como um saber instrumentalizador, capaz de fertilizar determinadas compreensões, e renovar, ao promover indagações teóricas. ${ }^{7}$ Por exemplo, Teoria psicanalítica, Teorias e técnicas psicoterápicas 1 , Fundamentos de psicanálise,
disciplinas optativas e de estágio orientadas pela abordagem psicanalítica etc. 
Ensinar se inclui, ao lado de governar e analisar, entre os ofícios impossíveis, como dizia Freud. Trabalhar como professor é uma tarefa que, acreditamos, torna-se muito árdua se feita sem a motivação advinda do desejo, se feita apenas sob o imperativo de ser uma atividade como "outra qualquer", pela qual se pode obter algum dinheiro para viver. ${ }^{8}$ (10) Não queremos com isto, de modo ingênuo, afirmá-la como vocação a ser exercida asceticamente, ou como uma virtude, descolada da sua condição de labor para o qual cabem perfeitamente as reivindicações feitas pela classe trabalhadora ao longo do tempo. $\mathrm{O}$ que queremos é sublinhar a relevância de que a escolha pela docência, quando feita pelo analista, seja marcada pelo desejo. Escolha advertida, capaz de produzir um trabalho realizado a partir do desejo e orientado por uma ética. Importante, pois, que o analista, uma vez respondendo da posição de docente, torne isto o seu "dever desejante", como gostava de dizer Emílio Rodrigué, ${ }^{(11)}$ que promova a transferência de trabalho, sabendo que a sua função é oferecer as condições para que o outro aprenda, para que o outro assuma o desafio de, por sua vez, tomar consciência do seu desejo e se deixar mobilizar.

\section{REFERÊNCIAS}

1. Freud S. Edição standard brasileira das obras completas de Sigmund Freud. Vol. 17, Sobre o ensino da psicanálise nas universidades (1919). Rio de Janeiro: Imago; 1987.

2. Lacan J. Escritos. Capítulo, A psicanálise e seu ensino [1957]. Rio de Janeiro: Jorge Zahar; 1998.

3. Rey S. "O que a psicanálise nos ensina, como ensiná-lo?” (na universidade). Rev Assoc Psicanal Porto Alegre 2005;12:48-56.

4. Dor J. Clínica psicanalítica. Porto Alegre: Artes Médicas; 1996.

5. Freud S. Edição standard brasileira das obras completas de Sigmund Freud. Vol. 20, A questão da análise leiga (1926). Rio de Janeiro: Imago; 1987.

6. Freud S. Edição standard brasileira das obras completas de Sigmund Freud. Vol. 18, Dois verbetes de enciclopédia (1923 [1922]). Rio de Janeiro: Imago; 1987.

\footnotetext{
${ }^{8}$ V. a tese de Freitas (2005), decorrente da sua pesquisa de doutorado na UnB. Resultado de uma investigação com professores da rede estadual privada de ensino é um trabalho que traz importantes contribuições à discussão sobre as questões aqui apontadas e várias outras, relacionadas à atividade docente.
} 
7. Azevedo AV. Novas e velhas Cilas e Caríbdis da análise leiga. Pulsional Rev Psicanal. 2003;16:7-13.

8. Miguelez OM. A formação em questão. Pulsional Rev Psicanal. 2005;17:119-23.

9. Souza O. Algumas dificuldades do ensino da psicanálise na Universidade. Pulsional Rev Psicanal. 2001;13:100-9.

10. Freitas CES. Trabalho estranhado em professores do ensino particular em Salvador em um contexto neoliberal [tese] - [Brasília (DF)]: Universidade de Brasília; 2005.

11. Rodrigué E. Sigmund Freud: o século da psicanálise: 1895-1995. São Paulo: Escuta; 1995. 